\title{
Percepción de riesgos socioambientales en tomas de terreno de Playa Ancha, Valparaíso (Chile). Los casos de Pueblo Hundido y Vista al Mar
}

\author{
Tania de Armas-Pedraza, Felipe Gascón-Martín \\ y Patricia Muñoz-Salazar*
}

Universidad de Playa Ancha, Chile

\section{Resumen}

Las tomas de terreno constituyen asentamientos poblacionales precarios e informales en donde se instalan los sectores más empobrecidos de las ciudades latinoamericanas. El artículo analiza los procesos de territorialización en dos tomas de terreno de Valparaíso (Chile), desde el enfoque de la vulnerabilidad y la producción social del riesgo. Se propone conocer los significados que los pobladores le asignan a los riesgos con los que conviven y tratar de identificar las acciones adoptadas para la prevención de catástrofes. Los resultados muestran sentimientos de marginación y exclusión del sistema urbano; conciencia de la precariedad del entorno y de las amenazas que los rodean. Sin embargo, sólo después de la tragedia se apela a la organización, sin que logre concretarse.

Palabras clave: Riesgo socioambiental, vulnerabilidad, tomas de terreno, gestión social del riesgo, territorialización, pobreza urbana.

\section{Abstract}

Perception of socio-environmental risks in land occupation of Playa Ancha, Valparaiso (Chile)

Land occupations are precarious and informal settlements where the poorest sectors of Latin American cities are installed. The article analyzes the territorial processes into two land occupations of Valparaiso (Chile) using the approach of vulnerability and social risk management. It aims to identify the meanings that people assign to the risks with which they live and try to identify the actions taken to prevent disasters. The results show feelings of marginalization and exclusion of the urban system. Also people are aware of the precariousness of the environment and the threats that surround them. However, they are not organized, relying on neighborhood solidarity to solve the problems. Only after the tragedy, they appealed to organization, without achieving its materialization.

Key words: Social and environmental risk, vulnerability, land occupations, social risk management, territorialisation, urban poverty.

* Agradecimientos: El presente artículo se enmarca en el Convenio de Desempeño Upa 1301 "Generación de conocimiento compartido: un modelo replicable de innovación social para el desarrollo territorial de Playa Ancha", financiado por el Ministerio de Educación de Chile. Agradecemos especialmente la colaboración como ayudantes de investigación de las estudiantes Katherine Jhonson y Consuelo Dinamarca. 


\section{INTRODUCCIÓN}

Lo legal y lo ilegal son las dos formas relevantes de existir ante el derecho (...) Esta dicotomía central abandona todo el territorio social donde la dicotomía podría ser impensable como un principio organizativo, ese es el territorio sin ley, lo a legal, lo no legal e inclusolo legal o lo ilegal de acuerdo con el derecho no reconocidooficialmente.

Boaventura de Sousa Santos

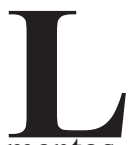

as tomas de terreno, como asentamientos poblacionales informales, han estado en el centro del debate social latinoamericano, recibiendo distintas nominaciones: poblaciones callampas, campamentos, asentamientos irregulares, precarios, favelas, etc., lo que muestra la pluralidad de perspectivas teóricas e investigativas desde las que se han abordado y los cambios socio históricos que han afectado sus dinámicas y características.

En las décadas de los 60 y 70, las tomas de terreno fueron comprendidas como resultados de los procesos de marginalización asociados a la industrialización/modernización en América Latina (Germani, 1967; DESAL, 1969; DESAL, 1970; Quijano, 1971; Nún, 1972). En los años 70-80, en el convulso contexto social y político vivido en el subcontinente, las tomas de terreno fueron entendidas como lugares de resistencia, como espacios de gran connotación política y una expresión material de lucha de clases, identificándolas como las situaciones más críticas de la problemática urbana (Castells, 1973; Garcés, 2002; Valladares y Prates, 2003). En los 90, en un contexto marcado por la restauración de las democracias neoliberales, las tomas son conceptualizadas como "campamentos" o "asentamientos irregulares", dando origen a una política de vivienda que buscaba disminuir el déficit habitacional. En este periodo, gran parte de la investigación se orientó a conocer los nuevos problemas derivados de la convivencia en grandes conjuntos de vivienda social, configurando el problema de los "con techo" (Rodríguez y Sugranyes, 2005) y la nueva "pobreza urbana" (Tironi, 2003). Esto llevó a una redefinición de la cuestión hacia un escenario de habitabilidad formal establecido por el Estado.

En la actualidad, las tomas constituyen una estrategia de los pobladores para reducir la segregación residencial, facilitar el acceso a la vivienda social y optar a una mejor localización dentro de la ciudad. Así, las tomas constituyen una respuesta a la provisión de vivienda social que habitualmente es periférica, alejada de los circuitos sociales y de las oportunidades que otorga el espacio urbano, aunque se ubiquen en emplazamientos riesgosos (Sabatini y Wormald, 2005; Brain, Prieto y Sabatini, 2010). 
Según el Ministerio de Vivienda y Urbanismo de Chile (MINVU, 2011), la región de Valparaíso concentra la mayor cantidad de campamentos ${ }^{1}$ del país (22.7 por ciento), alcanzando un total de 140 campamentos, los que agrupan a alrededor de 7531 familias. Más aún, el Gran Valparaíso² concentra 70 por ciento de los campamentos de la región, localizados en zonas geográficamente riesgosas, de difícil acceso y habitabilidad, como son los cerros, sus laderas y quebradas. Así una gran proporción de estos espacios enfrenta grandes desventajas, no solo por la lejanía, sino por el riesgo y las dificultades en el habitar; sin embargo, y a pesar de ello, existe escasa investigación que dé cuenta de estos fenómenos derivados de su particular geografía (Arellano, 2005; Kapstein, 2004).

En este artículo se analizan las tomas de terreno desde una perspectiva socioterritorial, es decir, como espacios afectados por procesos de territorialización, lo que significa que han sido apropiados por ciertas relaciones sociales e históricas que los van conformando, tanto en su materialidad, como en su construcción simbólica. En tanto espacios de relaciones sociales, los territorios que conforman las tomas de terreno son generadores de dinámicas de acción colectiva no exentas de conflictividad (Fernándes, 2005). El espacio de la toma se constituye entonces como un "territorio usado" (Santos, 1994), por cuanto sustenta la historicidad de los procesos de territorialización sujetos, a su vez, a inicidencias políticas, económicas y culturales. De este modo, los territorios usados contienen las acciones pasadas, ya cristalizadas en objetos y normas, pero también las acciones presentes, las que permiten comprenderlos como una forma/contenido, como un trazo de unión entre pasado y futuro, entre distintas escalas de espacio y tiempo, entre materialidad y vida social (Silveira, 2008), entre pertenencia y diferenciación-otredad, entre bordes y borderlands (Sánchez, 2015).

El presente trabajo persigue analizar las conexiones entre los procesos de territorialización y la acción colectiva, a fin de comprender las dinámicas en las que se producen las significaciones e interrelaciones de los individuos con el territorio. Acorde a este propósito, definimos como objetivo establecer el significado que las pobladoras y pobladores radicados en las tomas de terreno le asignan a los diferentes riesgos con los que conviven

\footnotetext{
1 "Campamento" es la forma adoptada por el discurso oficial de las políticas públicas para denominar a las tomas de terreno, reforzando así el carácter transitorio e itinerante del acampar al aire libre (excursionistas, turistas, tropas), aunque en el contexto habitacional de referencia su uso agrava el énfasis de informalidad y precariedad, cuya eficacia simbólica tiende a exponer a estas poblaciones a la incertidumbre permanente de la desconexión, traslado o erradicación.

${ }^{2}$ El Gran Valparaíso es una conurbación que agrupa a las comunas de Valparaíso, Viña del Mar, Concón, Quilpué y Villa Alemana, zona metropolitana de la capital regional de Valparaíso con una población total de un millón de habitantes (siete por ciento del país, según el censo de 2012).
} 
en esos territorios. Como contexto para entrar en dicha materia, en el mapa conceptual siguiente (Figura 1) presentamos una síntesis de los aspectos centrales del habitar y convivir que definirían la subjetividad identitaria de los pobladores y pobladoras de las tomas de terreno estudiadas.

\section{ANTECEDENTES CONCEPTUALES}

\section{Los desastres socioambientales}

El tema de los desastres ha sido estudiado sistemáticamente, existiendo enfoques teóricos, metodologías y experiencias en su gestión. Los organismos internacionales proporcionan asistencia e insisten en la necesidad que los esfuerzos locales mejoren su preparación y respuesta a las emergencias y catástrofes. Estos organismos consideran que el enfoque más efectivo para reducir los impactos de los desastres a largo plazo es la incorporación de la evaluación de amenazas y mitigación dentro de los procesos de planificación e inversión para el desarrollo (Fernández, 1996; MacDonald, 2005; Vergara, 2011) junto a políticas eficaces de organización y prevención (Morales y Alfaro, 2008).

Por otra parte, la gestión del ambiente urbano ha sido asumida tanto en el plano nacional como internacional, a través del desarrollo de tecnologías adecuadas para la provisión de servicios básicos de agua potable, alcantarillado, recolección de basura, control de contaminantes en el aire y procesos industriales. Pero no se ha trabajado una perspectiva que vincule la degradación ambiental de la ciudad y su vulnerabilidad frente a amenazas naturales o generadas por la acción humana, como amplificadoras de riesgos, emergencias y causa de desastres (MacDonald, 2005; Vergara, 2011).

La evidencia muestra que las manifestaciones de los fenómenos físiconaturales no se han incrementado, aunque sí el número de desastres, lo que lleva a interrogarse acerca de sus causas. Esto evidencia que los desastres deben ser considerados como hechos sociales, y no solamente como fenómenos físicos, lo que requiere del análisis del comportamiento humano frente a sí mismo y a la naturaleza. La región de América Latina está altamente expuesta a fenómenos geodinámicos como erupciones volcánicas, terremotos, maremotos y huracanes. Aunque a estos factores habría que agregarle la acción humana. Por ejemplo, si no se recolecta la basura, esta se deposita en los drenajes, tapándolos y provocando inundaciones toda vez que llueve. Cuando la inundación ocurre, se le tacha de evento excepcional, aunque el grupo humano lo fue construyendo paulatinamente, sin querer verlo (Fernández y Rodríguez, 1996; Kuroiwa, 2002; Vergara, 2011), invisibilizando de esta forma la ausencia de políticas de Estado pertinentes o la acción irresponsable de particulares. 
Percepción de riesgos socioambientales en tomas de terreno... / T. DE ARMAS-PEDRAZA et al.
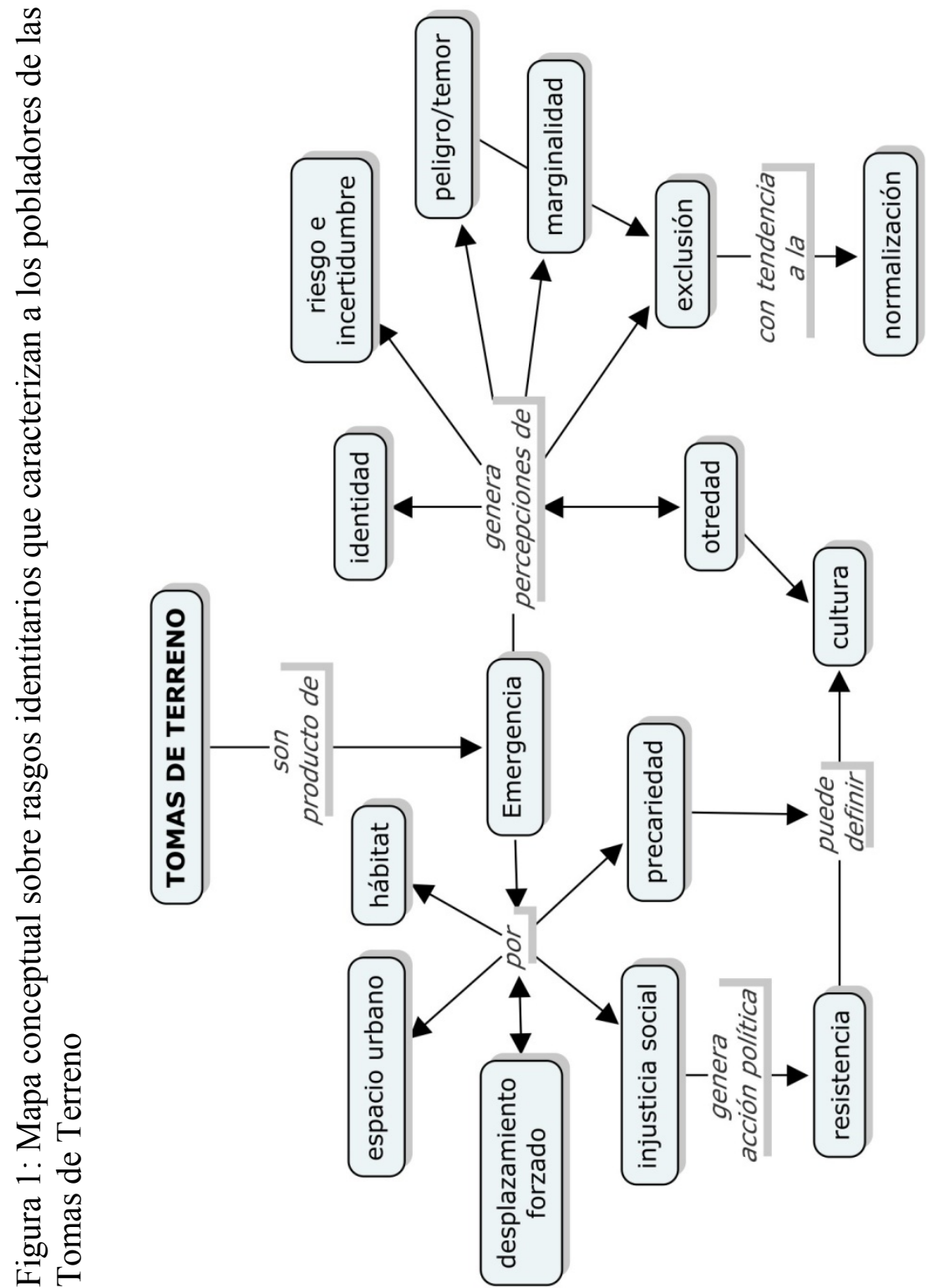
Así se tiene que por necesidad, interés o ignorancia, los diferentes grupos sociales van degradando lentamente el ambiente que les rodea, aumentando la vulnerabilidad, o bien potenciando las amenazas, sean estas de origen natural o antrópico. Los efectos se van acumulando, hasta que sobreviene la sorpresa, el desastre mal llamado "natural" que nadie esperaba, pero que todos construimos día a día, año con año. De este modo, la (in) actividad humana constituye la principal causa de degradación ambiental (Fernández y Rodríguez, 1996; Kuroiwa, 2002; Vergara, 2011).

En general, los recursos y fenómenos naturales se constituyen en amenazas cuando aumenta la posibilidad que generen desequilibrios en un sistema social. Así, las aguas de ríos, mares y lluvia, el viento, los suelos y volcanes pueden producir inundaciones, aluviones, deslizamientos de terreno, erupciones, terremotos y maremotos. Cuando un sistema natural produce un evento necesario para mantener su equilibrio, pero altera el funcionamiento habitual de un grupo social, se le considera peligroso y a sus consecuencias como un desastre. Por otra parte, cuando un sistema social genera un desequilibrio en un ecosistema, con acciones que provocan contaminación y deforestación, las consecuencias diarias no son visualizadas como micro-desastres. Solo cuando estas pequeñas, pero continuas, acciones desestabilizadoras se acumulan y se manifiestan en un evento catastrófico, entonces se percibe el desastre (Fernández y Rodríguez, 1996; Kuroiwa, 2002; Vergara, 2011).

\section{El enfoque de la vulnerabilidad y la gestión social del riesgo}

En general, se suele considerar a los desastres naturales como situaciones no resueltas del desarrollo. El modelo de desarrollo imperante genera las condiciones sociales, políticas, económicas e institucionales, que propician condiciones favorables para que ocurran los desastres. Sin embargo, estas condiciones, a pesar de ser muy aceptadas, no han sido suficientes como para que quienes toman decisiones incorporen medidas para que el modelo de desarrollo se conciba en forma pertinente, participativa, y se implemente de modo seguro en sus escenarios locales (Thomas, 2011).

Las condiciones que se supone promueven el desarrollo, no operan de manera adecuada en los países subdesarrollados, en los que el crecimiento económico se trata de alcanzar con un uso intensivo de energías y materias primas. La demanda por estos recursos ha generado condiciones inseguras que afectan a amplios sectores de población, produciendo vulnerabilidades y posteriores desastres. Habitualmente, estas son condiciones inseguras producto del predominio de intereses particulares y empresariales 
que desconocen los impactos y degradaciones ambientales en su intento de apropiación de los recursos naturales y de su posterior transformación (Thomas, 2011).

Las causas estructurales de las vulnerabilidades han generado condiciones perjudiciales para la población, ya que con la concentración poblacional en áreas urbanas en condiciones precarias de suelo, materiales de construcción, servicios públicos domiciliarios, equipamiento colectivo y localización en zonas marginales, incrementan la aparición de problemáticas sociales, conflictos y los riesgos de sufrir efectos devastadores ante eventos naturales, como un temporal de viento o de lluvia intensa (Lavell, 2008).

Los puntos antes planteados llevan a considerar los riesgos y peligros como condiciones agravantes de la vulnerabilidad ante eventos potencialmente destructivos. Esto hace necesario precisar que los desastres, además de no ser naturales, no ocurren, sino que se manifiestan (Calderón, 2001). Con estas precisiones se aclara que aquellas concepciones de riesgo basadas exclusivamente en el evento natural, han llevado a que las políticas públicas se orienten a la construcción de obras de infraestructura destinadas a disminuir el impacto del evento, pero no a identificar las condiciones sociales, políticas, económicas o institucionales que convierten a las comunidades en vulnerables/vulneradas ante ese evento en particular.

Debido a que la ocurrencia de los desastres y su magnitud está estrechamente relacionada con las estructuras de saber-poder (Foucault, 1969; Santos, 2013) que conforman a una sociedad, se habla de la construcción social del riesgo para hacer referencia al peso que tienen en su contingencia e impacto las condiciones de pobreza, exclusión y marginalidad de las poblaciones, que las hacen altamente vulnerables a agentes externos (Thomas, 2011). Esto resulta ser particularmente cierto en el caso de muchos países de América Latina, pues las cifras de desastres generados por eventos naturales son mayores que otras regiones del mundo, al igual que la pérdida de vidas humanas y animales, así como de recursos económicos (CRID, 2007), especialmente asociados a viviendas y enseres domésticos.

El concepto de construcción social del riesgo conduce a que su tratamiento no se realice de modo reactivo, es decir, a actuar solo después de haber sufrido un evento destructivo, a fin de volver a las condiciones de equilibrio en que estaban las comunidades antes que ocurriera el evento. Este proceder no resuelve el problema, puesto que es precisamente la normalización de estas condiciones precarias la que genera la vulnerabilidad de la población. Por el contrario, se propone que una vez que se ha 
enfrentado la emergencia con acciones de rescate, atención y rehabilitación inicial, en la fase de reconstrucción, se incorporen las modificaciones estructurales de esas condiciones que hicieron vulnerable/vulnerada a la población. Esto significa que hay que enfrentar la reconstrucción con transformación, a fin de reducir la vulnerabilidad (Lavell, 2008). Ello implica pasar de una gestión compensatoria a una gestión prospectiva, no solo del riesgo, sino de la propia concepción del desarrollo, teniendo claro que no se trata de reparar las imperfecciones que se han ido consolidando a través de un modelo de desarrollo desigual, sino que es necesario generar las condiciones presentes y futuras para que las fallas no se vuelvan a producir (Thomas, 2011), asumiendo una perspectiva holística, ética y de derechos humanos para el Buen Vivir (Acosta, 2013).

La gestión social del riesgo constituye un proceso institucional y social mediante el cual se debe trabajar en red, con un sentido horizontal y vertical para articular una serie de políticas, actores, estrategias, instrumentos y acciones que buscan prevenir, mitigar y reducir, coyunturalmente, los elementos y niveles de exposición de las comunidades frente a aquellos eventos potencialmente destructores. Al mismo tiempo se debe incrementar su capacidad de respuesta, ajuste y recuperación, frente a los efectos adversos (Arteaga, 2006).

La gestión social del riesgo implica no sólo la reducción mecánica del riesgo, sino que se basa en el reconocimiento y la concientización social de que ciertas prácticas económicas, políticas, institucionales, sociales y culturales dan origen a desigualdades que exponen diferencialmente a la población a eventos potencialmente destructores. Ante dichos eventos, los más vulnerables tienen menor capacidad de organizarse para afrontarlos, asimilarlos y superarlos. Debido a esto, se propone promover la generación de espacios de convergencia de lo social y lo institucional a fin de incorporar a los diferentes estratos socioeconómicos, a los diferentes niveles de gestión pública y territorial, a los diferentes grupos de interés y opinión, en la comprensión de cómo se construye un riesgo social y los niveles de responsabilidad y corresponsabilidad social que le cabe a cada uno de los actores (Thomas, 2011).

Sin embargo, la respuesta de la población frente a los desastres no es automática ni lineal, sino que a menudo se ve matizada por las experiencias del colectivo, las actitudes, los valores y, en general, por los ámbitos normativos, cognoscitivos y simbólicos que cobijan a una sociedad. Esto se debe a que un territorio se construye también desde la cultura de los grupos sociales que lo ocupan, conformando un paisaje cultural (Nogué, 2015) 
donde cada grupo construye sus relaciones y su cotidianeidad a partir de lo que considera riesgoso o seguro. Aunque en determinados contextos se llega a normalizar la incertidumbre o el estado de emergencia permanente.

Para algunos autores, el riesgo es una construcción cultural de la sociedad (García-Acosta, 2005), que se produce en su devenir histórico, a partir de la asociación entre las amenazas y determinadas condiciones de vulnerabilidad, que se construyen y reconstruyen con el tiempo. Así, la percepción pública del riesgo y su aceptación son construcciones colectivas que incluyen una dimensión histórico-temporal y hacen referencia a una matriz cultural determinada (Caram y Pérez, 2006).

Los riesgos son proposiciones fácticas y valorativas a la vez, definiendo estándares culturales sobre "una vida tolerable o intolerable". La pregunta ¿cómo deseamos vivir? conlleva a proposiciones que deben descifrarse en una relación interdisciplinar competitiva, ya que involucra en igual proporción "el conocimiento del saber técnico y la familiaridad con percepciones y normas culturales" (Beck, 2002: 219).

Los riesgos y la percepción de ellos son "consecuencias no deseadas" de la lógica de control, proyecto social y tecnológico del Estado-nación en la modernidad. De esta forma, las consecuencias de los riesgos, ponen en cuestión la afirmación de control del Estado-nación, de su relación estructural con la racionalidad instrumental (Weber, 1980), debido tanto a la globalización de los riesgos (calentamiento global, hoyo en la capa de ozono, etc.) como a las incertidumbres e indeterminaciones del diagnóstico de los riesgos. Aunque Weber no discute el concepto de "riesgo", "una de cuyas peculiaridades es la de haber perdido precisamente esta relación entre intención y resultado, racionalidad instrumental y control" (Beck, 2002: 221).

Para entender los riesgos socioambientales, se han propuesto diversos modelos, los que identifican cuatro elementos relevantes, analíticamente distinguibles, pero ligados entre sí, que dan cuenta de la complejidad del concepto. Estos son: la peligrosidad, la exposición, la vulnerabilidad y la incertidumbre (Natenzon, 2004).

- La peligrosidad se refiere al potencial de amenaza que implica cualquier fenómeno físico natural. En este sentido, cuanto más información se tenga respecto al fenómeno, mayor probabilidad de saber qué podría llegar a suceder y prevenirlo.

- La exposición dice relación a las construcciones materiales y la distribución de la población en el territorio. Es decir, todo lo susceptible para responder y enfrentar a la peligrosidad. Este componente 
se manifiesta territorialmente como una construcción histórica que entrelaza los procesos físico-naturales con las relaciones socioeconómicas, configurando determinados usos del suelo, una cierta distribución de la infraestructura, de los asentamientos humanos, de los servicios públicos y otros. En este caso, la exposición se manifiesta en la población y en las construcciones precarias emplazadas en asentamientos carentes de instalaciones de una red de agua al interior de la vivienda, sin conexiones de luz y gas.

- La vulnerabilidad remite a las estructuras socioeconómicas. Se trata de una característica de la sociedad, que previo a la ocurrencia de un evento desastroso, define la situación en que se encuentra la población para enfrentar un fenómeno catastrófico imprevisto.

- La incertidumbre, por su parte, pertenece al ámbito del (des/re)conocimiento de las amenazas y peligros, de su control técnico y la toma de decisiones, ubicándose a nivel de percepción de los grupos. Por este motivo, es necesario conocer los aspectos políticos y las percepciones de los actores sociales implicados en el proceso, ya que hay valores e intereses muy importantes en juego en la consideración de los propios actores.

La vulnerabilidad social y el riesgo ambiental se relacionan a partir de la distribución social del riesgo, la diferenciación del grado de peligrosidad e impacto latente, ya que en la sociedad actual tanto los riesgos como las riquezas son objeto de un reparto desigual. Pero como los riesgos generalmente son invisibles tienen un factor de irrealidad, debido a que aún no han ocurrido ni la emergencia ni el desastre. Sin embargo, hay que tomar posición frente a ellos ya sea impedirlos, evitarlos o negarlos. Los riesgos tienen un estatuto de realidad suspendida "ya-no-pero-todavía-no"- ya no confianza/seguridad, todavía no destrucción/desastre" (Beck, 2002: 215). Pero las percepciones de amenaza, incluso de emergencia, parecen estar latentes y predisponer estados psico-sociales de alerta, temor, pánico, poniendo en tela de juicio el poder de la (re)acción social, de las políticas públicas y la asistencia social. Eso hace que se enfrenten dos lógicas, la lógica positiva de la apropiación de bienes con la lógica de eliminación de riesgos, que es una lógica negativa (Beck, 1998).

Los riesgos son definidos como el campo de probabilidades de que a una población (personas, estructuras físicas, sistemas productivos, etc.), o segmento de la misma, le ocurra algún daño (Narváez, Lavell y Pérez, 2009). Para que exista un riesgo debe haber una amenaza o un peligro y la vulnerabilidad es la propensión a sufrir daños que exhibe algún componen- 
te de la estructura social o de la naturaleza. El riesgo es, en consecuencia, una condición potencial, cuyo grado va a depender de una ecuación social: la intensidad probable de la amenaza y los niveles de vulnerabilidad existentes, en donde la vulnerabilidad representa el conjunto de atributos de un determinado sistema social que disminuye su capacidad de respuesta frente a las amenazas.

En la tríada peligrosidad-riesgo-vulnerabilidad, este último es un componente eminentemente social, referido a aquellos factores que derivan de la actividad humana y funcionan como condiciones intervinientes para incrementar el daño que ciertos fenómenos pueden causar. Desde esta perspectiva, se considera que si lo característico de las sociedades humanas es el riesgo, esto último no necesariamente tiene que derivar en desastre. De hecho, todo proceso de cambio social presupone cualidades e intensidades distintas de incertidumbre, riesgo y conflicto. Pero el desastre tiende a precipitarse con mayor probabilidad cuando el riesgo se suma a la vulnerabilidad.

\section{ANTECEDENTES EMPÍRICOS}

En el caso de Chile, una rápida revisión de la última década da cuenta de cómo los desastres recorren la larga extensión de su geografía. La inundación en 2006 que afectó seriamente a la población más humilde de la ciudad de Concepción; en 2008 la erupción del Volcán Chaitén que desplazó a la totalidad de los habitantes de esa localidad austral; en febrero de 2010, el terremoto y maremoto que golpeó a Chile central (Romero, 2014). En marzo de 2012, los aluviones arrasaron diversos asentamientos rurales de la árida región nortina de Tarapacá. En abril de 2014, nuevamente el Norte de Chile sufrió la destrucción de múltiples sectores de población e infraestructuras de comunicación debido a un terremoto de magnitud 8,2 en la escala de Richter, que implicó el desplazamiento de grandes cantidades de población ante la amenaza de posibles tsunamis. En el mismo mes de abril, el día 12, se inició el mayor incendio urbano de la historia de Chile, desbordando en la ciudad de Valparaíso toda capacidad de respuesta: 1100 hectáreas arrasadas por las llamas, tres mil casas devastadas, 16 fallecidos, 15 mil personas perdieron sus hogares junto a la historia familiar que creían a resguardo. Entre el 23 y 25 de marzo de 2015 un inusual temporal azotó a tres regiones del norte de Chile, Antofagasta, Atacama y Coquimbo, provocando inundaciones y aluviones debido al desborde de múltiples cauces de ríos. Una cincuentena de víctimas y un número de damnificados cercano a los 30 mil fue el saldo de un desastre cuyo origen, según estudios cien- 
tíficos, serían consecuencia de los asentamientos habitacionales en zonas de riesgo. Y mientras se concluía el presente trabajo, el 16 de septiembre, un terremoto de magnitud 8.4 grados en la escala de Richter, con epicentro en el sur de la Región de Coquimbo, situada en el denominado norte chico chileno, vino acompañado de un tsunami de diversa consideración en la costa centro-norte, junto a múltiples réplicas sísmicas, causando 15 muertos e incalculables pérdidas en infraestructuras públicas, viviendas, vehículos y flotas pesqueras.

Un estudio realizado en la ciudad de La Serena, IV Región, sobre la percepción del riesgo ante la amenaza de maremoto evaluó la capacidad de autoprotección y autogestión, según el nivel socioeconómico de la población de dicha localidad. Las respuestas varían en función de la exposición a la amenaza y al nivel de vulnerabilidad socioeconómica, en el sentido que en las zonas de menor vulnerabilidad se aprecia una considerable exposición frente a un tsunami, especialmente en la zona colindante al eje Avenida del Mar, donde en épocas estivales alberga a una gran cantidad de población flotante, por lo cual está en constante observación (Cid, 2012).

El estudio antes mencionado muestra que la población estudiada no tiene un adecuado nivel de conciencia de la necesidad de autoprotección y autogestión. También se observa que los factores asociados a la vulnerabilidad, están más vinculados a aspectos sociales que a la amenaza, concordando entonces con el carácter social del riesgo que se ha desarrollado en los puntos anteriores, en que se plantea que este surge del proceso de interacción continua y permanente entre la comunidad humana y su entorno. De este modo, la percepción del riesgo aparece como un criterio relevante asociado a la vulnerabilidad. Sin embargo, en el caso estudiado, los distintos estratos socioeconómicos mostraron patrones dispares. De este estudio, se puede inferir que los "imaginarios" varían según el contexto, el estrato socioeconómico y que, en general, existe una aversión al riesgo que puede ser traducida en una subestimación o negación de los individuos al verse involucrados en una situación de riesgo (Cid, 2012).

Otro estudio relevante sobre una experiencia social frente al riesgo, fue el realizado a propósito de los estragos provocados por la tormenta Henriette, que asoló Llano Largo y otros sectores en la Zona Diamante de la ciudad de Acapulco, en el año 2007. Se trata de un territorio de la periferia urbana marcado por la heterogeneidad social y cultural, en el que se desarrollaron dinámicas de participación que impulsaron una organización que, aunque incipiente y aun limitada, ha emprendido un camino para comprender y manejarse en una realidad plagada de riesgos (Rodríguez et al., 
2012). El estudio aborda la participación de los actores fundamentales en los procesos de gestión de la emergencia y la reconstrucción después del desastre, con la finalidad de identificar los procesos socioculturales que contribuyeron a generar espacios favorables a la participación y construcción de una percepción orientada a enfrentar situaciones de riesgo (Rodríguez et al. 2012).

\section{Metodología}

La investigación realizada tuvo un carácter descriptivo, basada en una estrategia metodológica cualitativa. El universo del estudio quedó conformado por las 15 tomas de terreno existentes en Playa Ancha (Valparaíso). De ellas se seleccionaron los casos de Pueblo Hundido y Vista al Mar, utilizando el criterio de antigüedad. La primera por ser la más antigua, cuyo origen se remonta a 1970; la segunda por ser la más reciente, al haberse iniciado el año 2002. La diferencia de años en su constitución resulta un criterio relevante, en la medida que se presuponía que la temporalidad podría marcar diferencias en los procesos de organización, liderazgo y dinámicas sociales de esos territorios.

La técnica ocupada para la producción de los datos fue la entrevista en profundidad, que permitió escudriñar en la experiencia de actores claves situados en un contexto social, llegando a través de ella a identificar y caracterizar las acciones y vivencias de los sujetos y captar los sentidos asociados a las mismas (Delgado y Gutiérrez, 1995). En cada una de las tomas de terreno se entrevistó a pobladores que hubiesen desempeñado roles de liderazgo en el surgimiento de las tomas y, también, a quienes sin ocupar cargos tienen igualmente experiencia comprobada de la realidad que se vive en las tomas. Se realizó un total de 12 entrevistas, seis en Pueblo Hundido y seis en Vista al Mar.

\section{RESULTADOS. LOS RIESGOS SIGNIFICADOS EN LOS TERRITORIOS}

Los procesos de territorialización efectuados en las tomas de terreno han implicado que diversos grupos humanos se instalen en terrenos que no son de su propiedad, sobre los cuales edifican viviendas precarias, careciendo de servicios básicos como luz y agua. La acción colectiva efectuada por estos grupos ha llevado a la adquisición de algunas mejoras, como iluminación del espacio público, trazado de calles y otros. Sin embargo, ellos viven en territorios carenciados de servicios básicos, a los cuales, en oportunidades, acceden por vías ilegales, como por ejemplo "colgarse del 
cableado eléctrico" o realizando conexiones artesanales, con mangueras, desde alguna matriz de agua potable. A esto se suman los rasgos particulares de estos emplazamientos, donde la lluvia en invierno amenaza con múltiples riesgos: barrizales, corte de caminos, aislamiento, deslizamientos, enfermedades, etc. Y en el caso particular de la península que conforma el Cerro Playa Ancha, el fuerte viento que azota el área, invierno y verano, potencia significativamente la exposición al riesgo. Todo ello influye en la forma que los vecinos visualizan los diferentes riesgos y los significados que les asignan en su propio paisaje cultural (Nogué, 2012).

\section{El incendio como principal riesgo percibido}

En el caso de las tomas de terreno del presente estudio, el principal riesgo percibido por los vecinos es el incendio. Ellos han tenido dolorosas experiencias de incendios en el pasado, lo que hace que vivan en constante vigilancia ante la posibilidad de iniciarse $u_{n}{ }^{3}$, pues están conscientes que con el viento existente y la escasa distancia que separa las viviendas, el peligro de su propagación es altísimo, como lo ilustran los siguientes testimonios:

...el incendio, dos veces hemos estado a punto de quemarnos, la última vez que se quemaron las casas estaba la alerta pa' Pueblo Hundido, pero antes de eso casi nos quemamos, si po'; y el fuego llegó hasta el mismo camino y si no es por bomberos y los aviones que vinieron nos quemamos todos (Dña. Roxana, Pueblo Hundido).

...pero este año ha habido hartos focos de incendio, se fueron al límite, hasta acá atrás llegó el fuego (Dña. Fabiola, Pueblo Hundido).

Bueno lo que aquí pasa a veces son incendios, de algunos que prenden el pasto por aquí y allá. Por acá abajo a una señora se le quemó su piececita (Dña. Nancy, Vista al Mar).

El temor a los incendios tiene una larga data, pues mantienen el recuerdo de siniestros ocurridos en el pasado, experiencias traumatizantes que no olvidan:

Aquí se quemaron unos niñitos, en el año ' 89 , en un incendio, ahí justo se quemaron, fue terrible, yo tenía a mi hija guagüita, eso fue lo que a mí me marcó para siempre, porque yo vi, yo avisé, yo fui la primera que vio, eso, porque fue una cosa que me ha marcado... (Dña. Fabiola, Pueblo Hundido).

\footnotetext{
${ }^{3}$ El 2 de enero de 2017 se produjo un incendio incontrolable que afectó al sector de Puertas Negras del Cerro Playa Ancha, consumiendo casi por completo la toma de terreno de Pueblo Hundido.
} 
Los vecinos identifican algunos aspectos como los causantes de los incendios. Entre ellos destacan los cables de la luz, que al chocar con el viento producen chispas, como lo expresa la siguiente vecina:

...Los cables donde están tan colgados y hay tantos juntos, con la lluvia o los vientos hacen chispas. El otro día sonaban así como estallando en el palo de poste de acá al lado de mi casa, no pude dormir asustada, y nadie podía venir a arreglar. Eso nos preocupa también porque si salta una chispa a un casa, ustedes ven como son las casitas acá, vamos a prender todos. Y el riesgo que corremos todos nosotros que no nos van a poder ayudar, usted sabe que siendo toma... Mire acá el riesgo cuando llovizna, empiezan a chocar las cables, esa otra vez sonaban más de un mes y cuesta para encontrar a alguien que lo arregle; una que hay que pagarle, cobran 30 mil pesos, y juntamos la plata entre todos y todos quedamos colgados, pero hay veces que la gente no tiene la plata. Pero eso es lo más problemático (Dña. Nancy, Vista al Mar).

En otros casos, el origen del riesgo de incendio, procedería de los mismos vecinos, en el sentido que sus conductas de consumo de drogas, a lo que se suma el viento imperante en el sector, constituyen un peligro para los demás, como lo expresa una vecina:

...Acá hay mucho viento. Acá somos mi vecina y yo, pero después se puso una casita allá, pero la persona después se fue y dejó la casita ahí..., entonces ahí se vino a empezar a dormir ese joven. Luchábamos pa' sacarlo, porque sabemos que es problema, porque son personas con drogas, se quedan dormidos con un cigarro, le hablamos, yo también le hablé al joven. Yo me iba a acostar y gritan "vecina incendio!", y con la oscuridad de la noche se veía un fogón y una llamará grande; quedé, pero, Dios mío, quedé traumá. Eso fue hace bastante tiempo (Dña. Natalia, Vista al Mar).

Los fuertes vientos de Playa Ancha, no sólo favorecen la difusión del fuego, sino que constituyen un peligro para las viviendas precarias en que habitan los vecinos Ellos tienen con frecuencia experiencias de techos que se desprenden y muros que caen, como comentan algunos de ellos:

... Aquí una vez una ventolera tan fuerte que levantó un techo completo y fue a dar al poste mío...de mi casa...pero afortunadamente esto quedó enganchado, y más encima lloviendo, menos mal que otros vecinos me ayudaron porque lata con lata... Si acá hay un viento demasiado fuerte... (Don Luis, Vista al Mar). 


\section{Percepción vecinal de otros riesgos}

El incendio no es el único riesgo percibido por los vecinos. Algunos, hacen referencia a las inundaciones: "La emergencia que tenimos es cuando se inunda la pasá. Aquí no más, se juntan las dos aguas, las aguas de acá, que corren del cerro y las otras que vienen por la calle y se vienen por acá" (Dña. Berta, Pueblo Hundido).

Otros vecinos se refieren a los caminos por donde transitan los vehículos, que son estrechos, no pavimentados, con curvas pronunciadas por la pendiente del cerro.

Mira aquí es el camino, cuando pasan los camiones. Ya la otra vez se cayó una camioneta en el techo de una casa po'. Es que aquí no tienen respeto. Justo aquí arriba hay un hoyo y cuando pasan los camiones pah! saltan y varias veces quedan colgando del borde y es súper peligroso porque uno aquí siente cualquier ruido, los choques. Una vez se cayó un auto ahí y un camión. La señora no estaba, cayó en todo el living... (Dña. Roxana, Pueblo Hundido).

"Los vehículos, donde vive la señora Natalia, en esa curva, que igual es media peligrosa, entonces ahí se hubo que hablar con los vecinos, pa' que pasaran más despacio. Porque una vez un auto casi se va pa' allá, no es na' que le quede la casa en el suelo, que se puede matar a alguien, por ahí anda un niño chico (Dña. Maricel, Vista al Mar).

Pa' mí, los autos cuando pasan por acá, los camiones, a veces pasan los camiones que vienen a dejar mudanzas, eso sí que me deja atacá. Yo ahora estoy luchando para hacer un camino ahí, pero ellos bajan y bajan, yo digo "uhy se va a dar vuelta", yo vivo asustada en ese sentido. He hablado con las personas que tienen vehículo. Porque en invierno queda la crema aquí, no pueden subir ni bajar, los vecinos llegan hasta abajo no más, me dejan en el estacionamiento. Me dan miedo los autos, yo digo "córranse pa' allá, córranse pa' allá". Ahí están tratando de arreglar para que pasen más pa' allá (Dña. Natalia, Vista al Mar).

También se menciona el humo que emana de hornos de una obra de ladrillos que existe en las cercanías:

Los hornos echan humo, ese problema hemos tenido con el humo. El humo de ladrillo es horrible, es tóxico. Como es el humo, cae po', primero sube y después cae. Y como aquí es bajo, a veces no se ve, parece niebla con tanto humo. Pero ahora creo que hacen más atrás los hornos, porque hubo harta denuncia. Es verdad po', si mis hijos estaban así... Imagínate mi mamá y mi niñita que son asmática también... (Dña. Fabiola, Pueblo Hundido). 
También destaca la preocupación por la salud de los vecinos, especialmente por los malos olores que predominan en el ambiente debido a la falta de alcantarillado

... por la salud sí, porque en el verano el olor y se llena de moscas. Porque allá corre de todo, está como estancado, la gente tira de todo, ha tirado basura, como te digo, cuando llueve, corre todo y como que se limpia. La otra vez el puente que está ahí, como que se bajó, una vez que llovió fuerte, nos quedamos en el puente un ratito, quedabas lleno de agua si te asomabas. En esas aguas viene de todo. Aquí nadie tiene pozo, o sea de esas que reciben cámaras, nadie, todo da a la quebrá (Dña. Fabiola, Pueblo Hundido).

Aquí no hay alcantarillado, hay pozos, está lleno de pozos, está lleno de bichos y en el verano es más fuerte. Por eso tengo cerrado pa atrás, pa que ellos no vayan a jugar allá. Hay mucho bicho, mucho ratón (Dña. María Teresa, Pueblo Hundido).

También viven con el temor a que la autoridad tome medidas sobre el territorio que ocupan de hecho y los desaloje o les corte el suministro de algún servicio que ocupan ilegalmente.

El temor que uno siempre tiene es que nos desalojen, es el miedo latente, yo creo que el de todos po'. Porque claro tu construi' algo aquí, pero tu sabi' que en cualquier momento te lo pueden quitar (Dña. Maricel, Vista al Mar).

Yo tengo miedo que me saquen el agua. Pa' mí sí; uno puede vivir sin luz, pero sin agua no sería lo mismo. Es un miedo como comunidad sí, pero también de forma personales (Dña. Natalia, Vista al Mar).

\section{Acciones comunitarias para enfrentar los riesgos}

$\mathrm{Al}$ indagar acerca de las formas en que la comunidad actúa y se organiza para enfrentar el peligro de incendio y otros, se observa que tal organización es inexistente y que no hay actividades o acuerdos entre vecinos tendientes a disminuir el riesgo, como lo ilustran las siguientes vecinas:

... mira, aquí nunca, nunca jamás han venido a limpiar todos los cerros, no, y los vecinos tampoco se ponen de acuerdo... Hay, por ser, casas que están metidas en todo el bosque, si uno les dice que tienen que despejar, yo les entrego folletos, pero no. Aquí viene Forestín todos los años a hacer cursos a los niños, pero ni con eso aprenden (Dña. Roxana, Pueblo Hundido).

No, siempre cuando han incendios decimos "vamos a limpiar" y en eso queda todo, es que la gente como que se las arregla solo, no piensa mucho en el vecino (Dña. Fabiola, Pueblo Hundido). 
Aquí no hay ninguna organización, cuando pasan las cosas, ya te digo, como caso incendios, como que toda la gente se mueve por sí sola, pero así de que esté programado en caso de un asalto, en caso de que se quieran meter a una casa, un sistema para avisar a los otros vecinos, no, nada (Dña. Mary, Pueblo Hundido).

Algunos vecinos están conscientes de su falta de organización, claro que son los menos.

Eso es negligencia de cada uno. Porque siempre hemos recalcado que corten el pasto. Y lo otro es falta de conciencia de la gente (Don Luis, Vista al Mar).

... Por eso uno dice "saquen el pasto" que fue lo que pasó ese incendio gigante que hubo en las tomas, uno dice "claro son tomas", pero influye mucho el ser humano ahí de cortar el pasto. Yo me atrevo a dar lecciones de eso porque soy yo la que limpio, tomo la escoba para evitar el pasto que se pueda correr pal lado, se corre independiente de que sea de la vecina, eso da lo mismo, es para evitar el incendio. Además que acá corre un viento, un viento terrible, cuando sale, sale... (Dña. Natalia, Vista al Mar).

Bueno aquí todos los vecinos ayudan, hacer cortafuegos, cortar las ramas... pero cuando el incendio ya está provocado eso sí. Previamente al incendio, es muy poca la gente que se preocupa de desmalezar y prevenir. Imagínate la gente que está más allá, cerca del cerro, del monte, más contacto con los matorrales. Y antiguamente cuando todavía no construían el camino costero que hay por acá (de la Pólvora) era más peligroso, porque ahora ese es un cortafuego natural que tenemos nosotros (Dña. Bernardita, Pueblo Hundido).

Los vecinos confían en la ayuda de sus pares para apagar los incendios. $\mathrm{Al}$ parecer, el riesgo generalizado que significa un incendio los hace confiar y confiarse de los vecinos que serán capaces de apagar el fuego, ya que las vías de acceso en las tomas son precarias y habitualmente la huella que han formado los pobladores no permite el tránsito de carros bomba o ambulancias.

La otra vez estuvimos cerca, como que hubo un incendio ahí, ahí partimos todos a echarle aguita, porque las bombas no tienen acceso, llegan hasta ahí arriba nomás (Don Luis, Vista al Mar).

Todos nos vamos a apagar el incendio porque es un riesgo total, así que andamos descuidados, de que alguien baje pa' abajo, vaya a dejar un cigarro, porque acá el pasto, este pasto en el verano se seca, entonces ahí viene el problema, hay que tener cuidado con la gente que baja y tira la colilla, tenemos que estar pendiente de eso (Dña. María Teresa, Vista al Mar). 
Esa vez vino bomberos y también vino gente de la población a ayudar, en ese sentido se destaca la gente de arriba, porque vinieron hartos jóvenes con palas a ayudar...de Edward Bello. O si no, habría quedado la... porque aquí, como te digo, nos quemamos todos no más po' ... (Dña. Fabiola, Pueblo Hundido).

En general, llama la atención la poca previsión con que los vecinos viven el día a día, pues no han logrado generar una organización para enfrentar las emergencias, ni han acordado algún sistema de alertas. Pensando lo anterior desde la lógica de la planificación territorial, pero no desde una racionalidad técnica sino desde la propia lógica de los vecinos, ellos están tan acostumbrados a vivir en el sector que han naturalizado los riesgos y no los ven como tales. Incluso los incendios -que es lo más mencionado- son vistos como una fatalidad, que hay que resignarse a vivir cuando la ayuda de los otros vecinos no alcanza a llegar o es insuficiente para apagar el fuego.

\section{Conclusiones}

Los procesos de territorialización implicados en el devenir de las tomas estudiadas deben comprenderse en el marco de las transformaciones más generales de la matriz sociopolítica que posibilita o condiciona estos procesos. En ese sentido, evidenciamos en los resultados de nuestro estudio la disolución de la matriz que históricamente había articulado en Chile la gestión de políticas públicas urbanas y habitacionales. Con esta matriz, Estado-partidos-sociedad (Garretón y Espinosa, 1992; Garretón, 2009), se había dado respuesta a los procesos de organización y movilización social, que condicionaban los procesos de integración, marginalidad y modernización socio-espacial. Como consecuencia de la fragmentación social iniciada en la dictadura militar y consolidada en el tiempo a través de la aplicación de políticas sociales reproductoras del orden neoliberal, cuyo carácter asistencialista, focalizado, precarizador e individualista inspiran una insolidaria competencia por recursos siempre limitados. Los pobladores de las tomas de terreno habitan entre la pérdida de sentido de lo comunitario, el miedo al otro y la incertidumbre (Beck, 1998) frente a los poderes instituidos.

Desde la perspectiva de la construcción social del riesgo asumida en este trabajo (Caram y Pérez, 2006; Thomas, 2011), el riesgo se naturaliza cuando se gesta en condiciones de alta vulnerabilidad estructural, como la característica de los contextos de estudio. Por dicha razón, los pobladores de las tomas analizadas asumen la condición de ser ciudadanos exclui- 
dos (Santos, 2013), marginados del sistema urbano y vulnerados en derechos fundamentales, como lo son una calidad de vida y vivienda dignas. Esa condición alimenta la fragilidad e inseguridad con que resuelven sus infraestructuras físicas, servicios básicos y energéticos, sometiéndolos finalmente a un estado de emergencia permanente. Esto confirma la ecuación de que la intensidad en la percepción de la amenaza ante los diversos riesgos a los que se ven expuestos se ve potenciada por los altos niveles de vulnerabilidad (Calderón, 2001; Thomas, 2011). Ello se explicaría por factores concadenados, como son la falta de conexión con las redes e infraestructuras de apoyo del sistema público de emergencias, la escasa organización colectiva para enfrentar posibles accidentes y desastres, junto a la inexistencia de formas autogestionadas de prevención, protección, acción oportuna y control de riesgos por causas naturales o antrópicas (Thomas, 2011).

Desde la propia historicidad narrada por los pobladores y pobladoras de las tomas de terreno de Playa Ancha en los procesos de territorialización estudiados, se construye una memoria traumática ante la pérdida de vidas humanas frente a riesgos que han devenido en tragedias, ratificando así una desesperanza aprendida, la incapacidad de enfrentar el riesgo o de conseguir la ayuda oportuna para salvar la vida de los habitantes más vulnerables de las tomas, los niños y ancianos.

Los fenómenos climáticos como el viento y la lluvia son percibidos aquí como las principales causas de exposición al riesgo, pues agudizan la precariedad de las infraestructuras y conexiones que realizan los propios pobladores o, en el mejor de los casos, algún trabajador con experiencia. En el caso del tendido eléctrico que alimenta de energía a las viviendas, el azote del viento sobre la insegura maraña de cables colgados a las torres de distribución provoca chispazos que pueden generar incendios y propagarse rápidamente por la misma acción del viento, a lo que se suma la precariedad de los materiales de construcción y la escasa distancia que separa las viviendas. Las fuertes rachas de viento en Playa Ancha, que en oportunidades supera los 100 a 120 kilómetros por hora, provocan también voladura de techumbres y derrumbe de muros.

La ubicación de las tomas de terreno en zonas cuyo complejo relieve dificulta en sí mismo la planificación de sus vías de acceso y la canalización adecuada de las aguas-lluvia -sometida a menudo al olvido tras prolongados períodos de sequía-, son otro factor percibido de riesgo por inundaciones cuando llegan los temporales en los años lluviosos. En estas, ocasiones son frecuentes los deslizamientos de laderas y las avalanchas 
de barro sobre las frágiles viviendas. De igual forma, lo accidentado de las vías de acceso, sin pavimentar, con fuertes pendientes y curvas peligrosamente cerradas, provocan accidentes a menudo. Así los choques, atropellos, desbarrancamientos y destrucción de viviendas, especialmente cuando transitan camiones de mudanzas que no conocen el sector, resultan eventos habituales. Con los temporales y el barrizal que producen, los automóviles quedan inmovilizados, bloqueándose el acceso a la población, al no poder subir ni bajar ningún vehículo.

También son factores percibidos como riesgosos por los pobladores y pobladoras de las tomas estudiadas los generados por las personas, bien sea por actividades productivas no reguladas o reguladas con anterioridad a los asentamientos y cuya toxicidad provoca riesgos a la salud de la comunidad, como también la contaminación por aguas servidas al carecer de alcantarillado, la proximidad de vertederos y basurales ilegales, que constituyen un factor determinante para las plagas de insectos y roedores.

Otras prácticas riesgosas producidas por las personas y que pueden ser amplificadoras del peligro y la amenaza de tragedias son las fogatas, la quema de pastizales y matorrales, el uso de velas al interior de la vivienda como sistema de iluminación, con mayor razón cuando son producto de conductas irresponsables que los vecinos asocian al descontrol por el abuso de alcohol y drogas.

De orden diferente es la percepción de riesgo que los pobladores tienen frente a las autoridades y las empresas de suministro de aguas y energías. El posible desalojo y el corte del suministro de servicios son dos componentes importantes que alimentan los temores entre los vecinos de ser desplazados del territorio.

Como se mencionó anteriormente, la pérdida de sentido político y comunitario de las tomas de terreno en la actualidad potencian la vulnerabilidad frente al riesgo, sea este motivado por razones naturales o antrópicas. Solamente después de la tragedia se activa la solidaridad o se apela a la organización colectiva, más como reacción que como una forma consciente y planificada de autogestión para prevenir riesgos y emergencias, que suelen tener resultados catastróficos en estos territorios de difícil acceso para los vehículos de emergencia, como los de bomberos o ambulancias.

La planificación urbana y la política habitacional enfrentan un gran desafío en este contexto, superar las visiones hegemónicas y unilaterales de erradicación a partir de la comprensión de la historicidad y el sentido de la territorialización de las tomas de terreno, una expresión de ciudadanía excluida que reactualiza las coloniales reducciones étnicas, generando 
ahora una particular reserva de sentido de otredad. Esta reducción o minorización afecta directamente al concepto de Estado-nación, la calidad de su democracia, al reconocimiento de derechos, hasta cuestionar la propia legitimidad ciudadana de los sin-tierra. En estos tiempos neoliberales de sobremodernidad y fragmentación social, nacen nuevas fronteras, límites y desbordes (Sánchez, 2015), nuevas segregaciones urbanas en este pericentro de emplazamientos desplazados en tiempo y espacio, en donde la invisibilidad y la estigmatización afectan a interacciones y redes sociales precarizadas respecto de las legítimas aspiraciones del Buen Vivir (Acosta, 2013). Para ello, se hace necesario incentivar políticas participativas superando ciertas racionalidades dicotómicas que pesan sobre la construcción ciudadana y que terminan reproduciendo nuevas vulneraciones en los derechos sociales: una integración excluyente, una normalización del (sobre) vivir en la emergencia, una ciudadanía emergente desde la invisibilizada exclusión.

\section{REFERENCIAS BIBLIOGRÁFICAS}

Acosta, Alberto, 2013, El Buen Vivir. Sumak Kawsay, una oportunidad para imaginar otros mundos, Icaria, Barcelona.

Arellano, Nelson, 2005, "Historia local del acceso al suelo. El caso de la ciudad de Viña del Mar", en Revista INVI, 54(20), disponible en http://revistainvi.uchile.cl/ index.php/INVI/article/view/328/892

Arteaga, Daniel, 2006, "De la gestión de desastres a la gestión de riesgo-análisis de la problemática existente en los sistemas de respuesta a desastres", en Cities on Volcanoes, 4, disponible en http://scielo-test.scielo.cl/scielo.php?script=sci arttext\&pid=S0718-34022011000100008\&lng=en\&nrm=iso

Beck, Ulrich, 1998, La sociedad del riesgo, Paidós, Barcelona.

Beck, Ulrich, 2002, La sociedad del riesgo global, Editorial Siglo XXI, Madrid.

Brain, Isabel, Prieto, José Joaquín y Sabatini, Francisco, 2010, "Vivir en campamentos: ¿Camino hacia la vivienda formal o estrategia de localización para enfrentar la vulnerabilidad?", en EURE, 109(36), disponible en http://www.eure.cl/ index.php/eure/article/view/123

Calderón, Georgina, 2001, Construcción y reconstrucción del desastre, Ediciones Plaza y Valdés, Ciudad de México.

Candia, David, 2005, Metas del milenio y tugurios: una metodología utilizando datos censales, Serie Población y Desarrollo 63, CEPAL/CELADE; División Población, Santiago de Chile. 
Caram, Mariana y Pérez, Soledad, 2006, "Entre el riesgo ambiental y el riesgo social: buscando una salida a la tenencia irregular", en Revista Argentina de Sociología, 6(4, disponible en http://revistainvi.uchile.cl/index.php/INVI/article/ view/565/1036

CASTELLS, Manuel, 1973, "Movimiento de pobladores y lucha de clases", en EURE, 7(3), disponible en http:/www.eure.cl/index.php/eure/article/view/834/694

Cid, Guillermo, Paz Castro, Carmen y Rugiero, Vanessa, 2012, "Percepción del riesgo en relación con capacidades de autoprotección y autogestión, como elementos relevantes en la reducción de la vulnerabilidad en la ciudad de La Serena", en INVI, 75(27), disponible en http://revistainvi.uchile.cl/index.php/INVI/article/ view/565/1036

CRID, 2007, Proyecto de fortalecimiento de un sistema de información municipal para la prevención de desastres en América Latina y el Caribe. Centro Regional de Información sobre desastres para América Latina y el Caribe (CRID), San José de Costa Rica.

Delgado, José Manuel y Gutiérrez, Juan (coord.), 1995, Métodos y Técnicas cualitativas de investigación en Ciencias Sociales, Síntesis, Madrid.

DESAL, 1969, Marginalidad en América Latina. Un Ensayo de Diagnóstico, Centro para el Desarrollo Económico y Social de América Latina (DESAL), Santiago.

Centro para el Desarrollo Económico y Social de América Latina (DESAL), 1970, La Marginalidad Urbana: Origen, Proceso y Modo, DESAL, Santiago de Chile.

Fernandes, Bernardo Mançano, 2005, "Movimentos socioterritoriais e movimentos socioespaciais: Contribuição teórica para uma leitura geográfica dos movimentos sociais", en OSAL, Observatorio Social de América Latina, 16(6).

Fernández, María Augusta (comp.) 1996, Ciudades en riesgo. Degradación ambiental, riesgos urbanos y desastres en América Latina. Red de Estudios Sociales en Prevención de desastres en América Latina, La Red.

Fernández, María Augusta y Rodríguez, Livia, 1996, “¿Cuál es el problema? Introducción a la temática”, en Fernández, María Augusta (comp.), en Ciudades en riesgo. Degradación ambiental, riesgos urbanos y desastres en América Latina, Red de Estudios Sociales en prevención de Desastres en América Latina, Lima, disponible en http://www.solucionespracticas.org.pe/Descargar/106/569

Foucault, Michel, 1969, La arqueología del saber, Siglo XXI, México.

Garcés, Mario, 2002, Tomando su sitio, El movimiento de pobladores de Santiago, 1957-1970, LOM, Santiago de Chile.

García-Acosta, Virginia, 2005, "El riesgo como construcción social y la construcción social de riesgos", en Desacatos (19) 11-24, disponible en http://www.scielo. org.mx/scielo.php?script $=$ sci_arttext\&pid $=\mathrm{S} 140592742005000300002 \& \operatorname{lng}=\mathrm{es} \&$ nrm $=$ iso

Garretón, Manuel Antonio y Espinosa, Malva, 1992, “¿Reforma del estado o cambio en la matriz sociopolítica?”, en Perfiles Latinoamericanos, 1(1). 
Garretón, Manuel Antonio, 2009, “Transformación de la matriz sociopolítica y desarrollo en Chile”, en Diplomacia, Estrategia y Política, núm. 9, enero/marzo.

Germani, Gino, 1967, "La ciudad como mecanismo integrador", en Revista Mexicana de Sociología, 29.

Kuroiwa, Julio, 2002, Reducción de desastres: Viviendo en armonía con la naturaleza. CISMID, Texas.

Lavell, Allan, 2008, Una visión de futuro: La gestión del riesgo, San José de Costa Rica, disponible en http://www.bvsde.paho.org/bvsacd/cd26/gestion_riesgos.pdf

Macdonald, Joan, 2005, La otra agenda urbana. Tareas, experiencias y programas para aliviar la pobreza y precariedad en las ciudades de América Latina y el Caribe. CEPAL, Santiago de Chile.

MINVU, 2011, Mapa Social de Campamentos, Serie VII. Política Habitacional y Planificación, Secretaría Ejecutiva de Campamentos, Ministerio de Vivienda y Urbanismo (MINVU), Santiago de Chile.

Morales, Nelson y Daniel Alfaro, 2008, "Génesis de las contingencias catastróficas: Etiopatogenia del desastres", en Revista Peruana de Medicina Experimental y Salud Pública, 1(25).

Narváez, Lizardo; Lavell, Allan y Pérez, Gustavo, 2009, La gestión del riesgo de desastres. Un enfoque basado en procesos. Comunidad Andina-PREDECAM, Perú.

Natenzon, Claudia, 2004, Desarrollo de una ciencia posnormal. Riesgo, vulnerabilidad e incertidumbre, Serie documentos de clase, núm. 5, GSU/FLACSO, Buenos Aires.

Nogué, Jordi (ed.), 2015. La construcción social del paisaje, Biblioteca Nueva, Madrid.

NÚN, José, 1972, "Marginalidad y otras cuestiones", en Revista Latinoamericana de Ciencias Sociales, 4.

Quijano, Aníbal, 1971, "La formación de un universo marginal en las ciudades de América Latina", en Castelles, M. y Vélez, P. (eds.), en Imperialismo y Urbanización en América Latina, Gustavo Gili, Barcelona.

Rodríguez, Alfredo y Sugranyes, Ana, 2005, Los con techo. Un desafio para la política de vivienda social, SUR, Santiago.

Rodríguez, América, Manuel Ruz y Hernández, Berenise, 2012, "Riesgo y vulnerabilidad en Llano Largo, Acapulco: La tormenta Henriette", en Economía, Sociedad y territorio, 39(12), disponible en http://est.cmq.edu.mx/index.php/est/article/ view/77

Romero, Hugo, 2014, "Vulnerabilidad, resiliencia y ordenamiento territorial de los desastres socionaturales en Chile", en Polígonos, Revista de Geografia, 26, disponible en http://revpubli.unileon.es/ojs/index.php/poligonos/article/view/1700 
Sabatini, Francisco, 2005, "Reforma de los mercados de suelo en Santiago, Chile: efectos sobre los precios de la tierra y la segregación residencial", en Revista EURE, 77(23), disponible en http://www.eure.cl/index.php/eure/article/view/1194

Sabatini, Francisco y Wormald, Guillermo, 2005, "Santiago de Chile bajo la nueva economía (1980-2000). Crecimiento, modernización y oportunidades de integración social", en Portes, Alejandro, Roberts, Bryan R., Grimson, Alejandro (eds.), Ciudades Latinoamericanas. Un análisis comparativo en el umbral del nuevo siglo, Prometeo, Buenos Aires.

Sánchez, Luis, 2015, "De territorios, límites, bordes y fronteras: una conceptualización para abordar conflictos sociales", en Revista de Estudios Sociales, 53 DOI: http://dx.doi.org/10.7440/res53.2015.14

Santos, Boaventura de Sousa, 2013, Descolonizar el saber, reinventar el poder, Lom-Trilce, Santiago.

Santos, Milton, 1994, "O Retorno do Territòrio", en Santos, Milton, Silveira, Maria Laura y de Souza, Maria Adélia (org.), en Territòrio, Globalizaçao e Fragmentação, Hucitec-ANPUR, Sao Paulo.

Silveira, Maria Laura, 2008, “Globalización y territorio usado: Imperativos y solidaridades", en Cuadernos del CENDES, 69(25).

Tironi, Manuel, 2003, Nueva pobreza urbana. Vivienda y capital social en Santiago 1985-2001, RIL, Santiago de Chile.

Thomas, Javier, 2011, “Desarrollo y gestión social del riesgo: ¿Una contradicción histórica?", en Revista de Geografía Norte Grande, 48.

Valladares, Licia y Prates, Magda, 2003, La investigación urbana en América Latina. Tendencias actuales y recomendaciones. Documentos de Debate núm. 4. UNESCO, disponible en http://unesdoc.unesco.org/images/0010/001008/100873sb.pdf

Vergara, Ricardo, 2011, Vulnerabilidad en grandes ciudades de América Latina, Editorial Universidad del Norte, Barranquilla.

Weber, Max, 1980, Economía y sociedad, FCE, México.

\section{RESUMEN CURRICULAR DE LOS AUTORES}

\section{Tania de Armas Pedraza}

Doctora en Procesos Sociopolíticos de las Sociedades Latinoamericanas por la Escuela Latinoamericana de Postgrado de la Universidad ARCIS, Santiago de Chile. Licenciada en Sociología por la Universidad de La Habana, Cuba. Profesora Asociada y Directora del Departamento de Sociología de la Universidad de Playa Ancha e investigadora del Observatorio de Participación Social y Territorio de la Facultad de Ciencias Sociales. Líneas de investigación: género, feminismos, acción colectiva, memorias. Dirección electrónica: tania.dearmas@upla.cl 


\section{Felipe Gascón Martín}

Doctor en Ciencias de la Comunicación por la Universitat Autònoma de Barcelona, Posgraduado Cátedra UNESCO-Brasil en Comunicación y Políticas Públicas. Decano y Profesor Titular en la Facultad de Ciencias Sociales de la Universidad de Playa Ancha (Valparaíso, Chile). Investigador del Centro de Estudios Avanzados y del Observatorio de Participación Social y Territorio. Ha publicado más de 50 artículos y capítulos de libros en sus líneas de investigación: ecología política de la comunicación; comunicación y ciudad; memorias, diferencias e interculturalidad; estudios mediales y del discurso. Fundador de la Revista F@ro, socio fundador y directivo de la Asociación Chilena de Investigadores en Comunicación; integra diversos comités editoriales y es consultor de la Comisión Nacional de Investigación Científica y Tecnológica de Chile.

Dirección electrónica: fgascon@upla.cl

\section{Patricia Muñoz Salazar}

Ph.D. en Rural Sociology por la Pennsylvania State University (Estados Unidos), Magister en Ciencias Sociales por la Universidad de Chile, Licenciada en Sociología y Socióloga por la Universidad de Concepción. Ha participado en investigaciones y publicado artículos y capítulos de libros en temáticas relativas a la implementación de políticas de vivienda social, el desarrollo territorial a nivel local, la seguridad ciudadana y las problemáticas de los asentamientos informales. Profesora Asociada de la Universidad de Playa Ancha e investigadora del Observatorio de Participación Social y Territorio de la Facultad de Ciencias Sociales.

Dirección electrónica: pmunoz@upla.cl

Artículo recibido el 5 de enero de 2016 y aprobado el 24 de marzo de 2017. 